\title{
FUNCTIONAL DEVELOPMENT OF THE OLFACTORY BULB AND A UNIQUE GLOMERULAR COMPLEX IN THE NEONATAL RAT ${ }^{1}$
}

\author{
CHARLES A. GREER, ${ }^{, 2}$ WILLIAM B. STEWART, $\ddagger \S$ MARTIN H. TEICHER, ${ }^{*, 3} \Lambda$ ND \\ GORDON M. SHEPHERD* \\ Sections of *Neuroanatomy, $\ddagger$ Neurosurgery, and §Anatomy, Yale University School of Medicine, \\ New Haven, Connecticut 06510
}

Received May 17, 1982; Revised July 7, 1982; Accepted July 12, 1982

\begin{abstract}
The $\left[{ }^{14} \mathrm{C}\right] 2$-deoxy-D-glucose $(2 \mathrm{DG})$ technique was employed to study the ontogeny of functional organization in the olfactory bulbs of rats from birth to 21 days postnatal. These observations were correlated with the histological maturation of the olfactory bulb laminae. In 0-day pups (within 12 $\mathrm{hr}$ of parturition), foci of increased metabolic activity were elicited in the olfactory bulb by the odor of amyl acetate. The foci, generally poorly defined, were localized over the glomerular layer, which, in histological sections, was poorly differentiated. In suckling pups injected with $2 D G$, a single focus characteristically was observed in the main olfactory bulb near the medial border of the accessory olfactory bulb. In this region, a well differentiated complex of glomeruli was observed in the histological sections.

During the ensuing 21 days postnatal, the focal patterns of 2DG uptake in animals exposed to amyl acetate odor progressed through a series of changes, each of which could be related to parallel stages of development in the histology of the bulb. Particularly striking were the establishment of sharply defined 2DG foci and the formation of distinct individual olfactory glomeruli by the end of the 1st week. Generally, by 15 days postnatal, the adult patterns of 2DG uptake and histological lamination were established.

The modified glomerular complex also exhibited focal 2DG uptake beginning on day 0 , but these were better defined than those associated with the glomeruli of the main olfactory bulb. This observation correlated with the more advanced histological differentiation of this specialized region. These data suggest that the modified glomerular complex may mature earlier than other regions of the olfactory bulb. This earlier maturation may reflect the importance of the modified glomerular region for processing odor cues relevant to suckling behavior in neonatal rats.

Taken together, these results provide evidence for several successive changes in the functional organization of the developing olfactory system of neonatal rats.
\end{abstract}

The neural substrates of olfactory function in the neonatal rat are not well understood. Behavioral studies generally agree upon the critical role of olfaction during the perinatal period of development (Blass and Teicher,

\footnotetext{
${ }^{1}$ We would like to thank Dr. John S. Kauer for valuable discussions and development of the computer-assisted reflectance densitometry program, Dolores Montoya and Janina Casby for their excellent technical assistance, and Kathleen Kiley for secretarial assistance. This research was supported in part by National Instilute of Neurological and Communicative Disorders and Stroke Grant F32-NS06159 to C. A. G., National Science Foundation Grant BNS-78-16545 to G. M. S., and National Institutes of Health Grant NS-10174 to William F. Collins.

${ }^{2}$ To whom correspondence should be addressed at Section of Neuroanatomy, Yale University School of Medicine, 333 Cedar Street, New Haven, CT 06510.

${ }^{3}$ Present address: Department of Psychiatry, McLean Hospital, Boston, MA 02154.
}

1980; Teicher and Blass, 1976, 1978; Leon, 1974). Although olfactory function can be demonstrated in the neonate, acuity is low (Rudy and Cheatle, 1977; Alberts and May, 1980a, b). In electrophysiological studies, spontaneous EEG activity has not been observed in the rat olfactory bulb prior to 3 days postnatal (Salas et al., 1969), although single unit analyses report spontaneous mitral cell activity within $12 \mathrm{hr}$ postnatal (Math and Davrainville, 1980a, b).

Few anatomical studies of the rat olfactory bulb during development have been reported (Altman, 1966; Singh and Nathaniel, 1978; Rosselli-Austin and Altman, 1979). The more extensive work on the mouse (Hinds, 1968a, b; Hinds and Hinds, 1976a, b) suggest that, at birth, the basic neuronal elements and synaptic types, although low in number, are present. Similarly, mature and seemingly functional olfactory receptor cells are present in the 
olfactory epithelium as early as embryonic day 17 (Monti-Graziadei et al., 1980).

A nonintrusive measure of physiological activity which could be correlated with morphology would be ideal for studying the ontogeny of structure and function in the olfactory bulb. In previous studies, we have shown that the $\left[{ }^{14} \mathrm{C}\right] 2$-deoxy-D-glucose (2DG) technique (Kennedy et al., 1975) can be used to demonstrate principles of functional organization in the olfactory bulb of the adult (Sharp et al., 1975, 1977; Stewart et al., 1979; Greer et al., $1981 \mathrm{a}, \mathrm{b})$. In addition, recent work has shown that the odor-specific patterns of $2 \mathrm{DG}$ uptake characteristic of the adult also can be identified in the 9- to 12-day postnatal rat (Teicher et al., 1980; Greer et al., 1980). Furthermore, this work identified a unique glomerular grouping, the modified glomerular complex, which appeared to be stimulated by putative pheromones associated with suckling behavior in the neonatal rat.

In the present report, we extend these earlier findings by demonstrating with the 2DG technique functional organization in the olfactory bulb within a few hours of birth and correlating our observations with the histological differentiation of the laminae. We then establish the time course for the maturation of the functional and anatomical organization into the adult characteristics. The modified glomerular complex was identified in the 0 -day animal and the data indicate that it matures earlier than the glomeruli of the main olfactory bulb. The results suggest that odors of behavioral significance to the neonatal rat are processed in areas of the olfactory bulb which may mature anatomically and functionally earlier than surrounding regions.

\section{Materials and Methods}

The data reported in this paper were obtained from 76 neonatal Sprague-Dawley rats. Pregnant multiparous females were purchased (Charles River Laboratories) and the time of parturition was recorded accurately to within $12 \mathrm{hr}$. The litters were culled to a maximum of 8 pups. As described below, pups either were tested with 2DG during controlled exposure to a nonodorized environment, to the odor of amyl acetate, or to odors present during suckling behavior or were prepared for histological examination on postnatal day 0 (within $12 \mathrm{hr}$ of parturition) and at 3, 6, 9, 12, 15, 18, and 21 days postnatal.

The amyl acetate odor exposure with 2DG generally followed procedures described previously (Sharp et al., 1977; Stewart et al., 1979). Briefly, 4 pups from each age group were employed. Each was removed from its dam approximately $1 \mathrm{hr}$ prior to testing and was maintained in a warm environment. Following an intraperitoneal administration of $200 \mu \mathrm{Ci} / \mathrm{kg}$ of $\left[{ }^{14} \mathrm{C}\right] 2$-deoxy-D-glucose (New England Nuclear) in physiological saline, the pup was placed in the odor exposure chamber (Stewart et al., 1979) and a $10^{-1}$ flow dilution of saturated amyl acetate
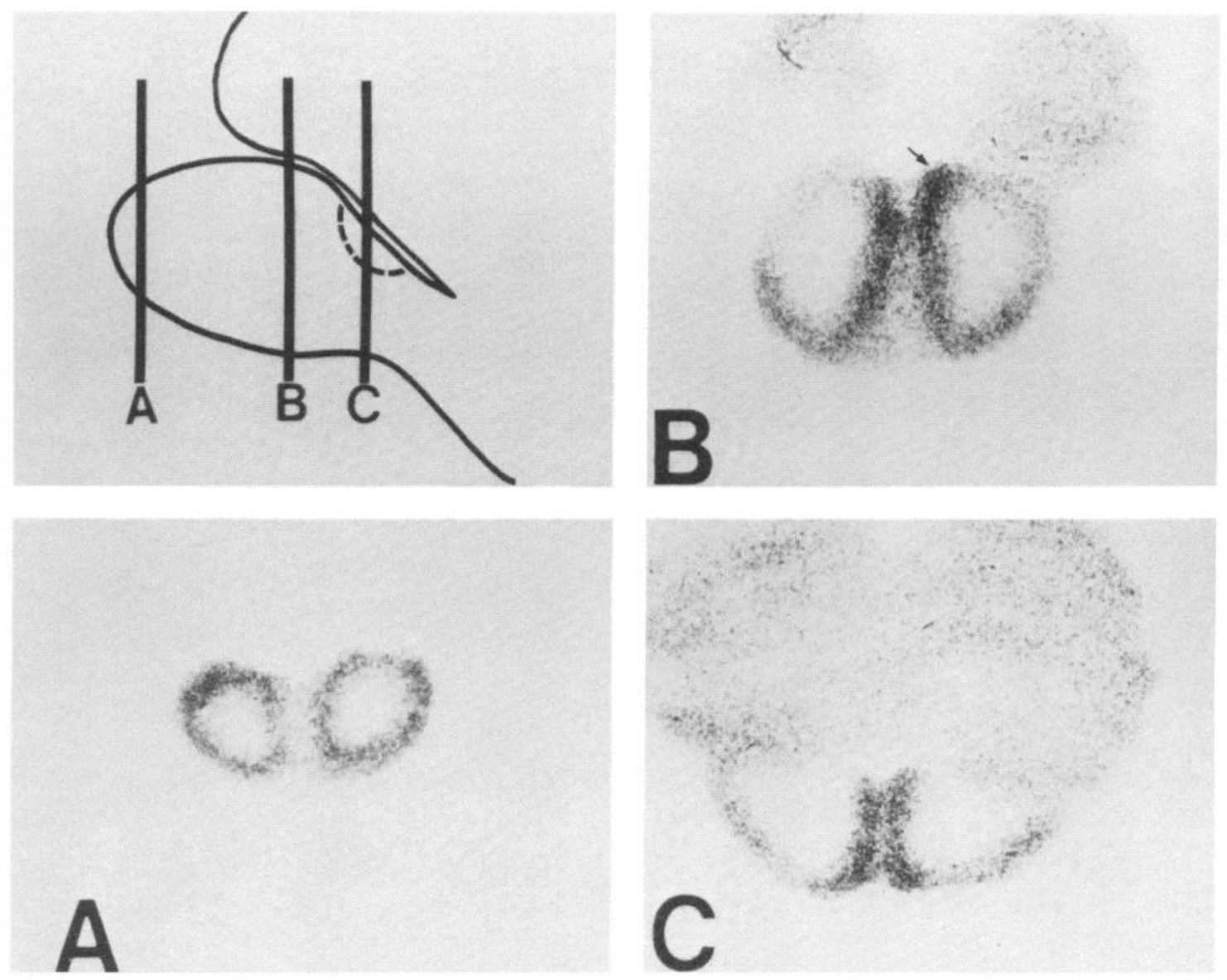

Figure 1. Autoradiographs from the olfactory bulbs of a typical 0-day postnatal rat exposed for $1 \mathrm{hr}$ to a $10^{-1}$ flow dilution of amyl acetate. The schematic diagram is a sagittal view of the olfactory bulb indicating the level of each of the three autoradiographs shown in $A, B$, and $C$. The arrow indicates the area of increased $2 \mathrm{DG}$ uptake. 

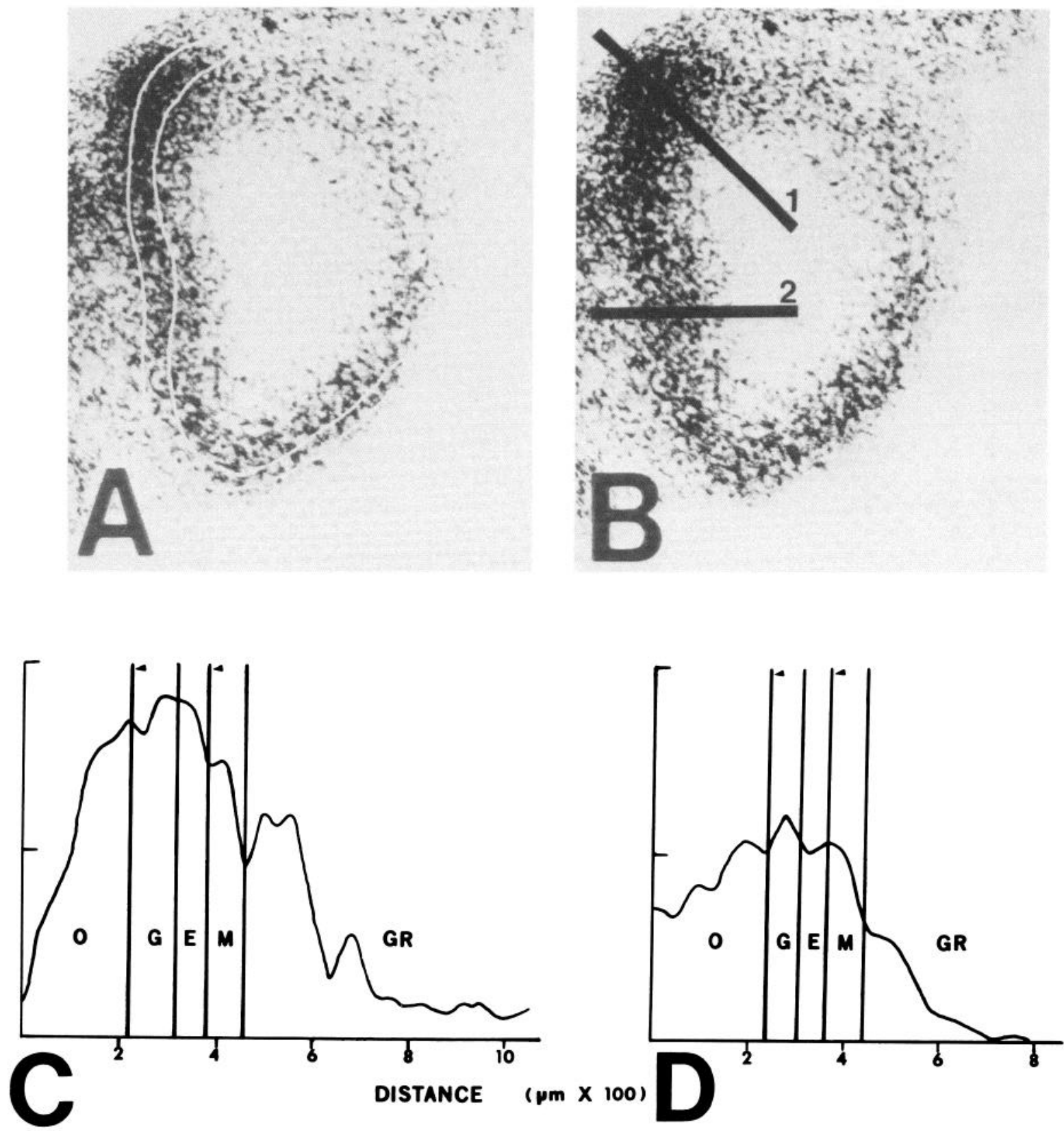

Figure 2. Histological correlation and cross-laminar reflectance optical density scans of the right olfactory bulb shown in Figure $1 B$. In $A$, outlines of the mitral body layer and the inner border of the olfactory nerve layer are superimposed upon the autoradiograph from the corresponding histology. In $B$, the lines indicate the paths of the densitometry scans shown in $C$ and $D$ which illustrate relative optical density across the laminae of the olfactory bulb. The vertical lines mark the individual laminae. The two arrowheads in $C$ and $D$ indicate the laminae superimposed upon the autoradiograph shown in $A$. $O$, olfactory nerve layer; $G$, glomerular layer; $E$, external plexiform layer; $M$, mitral body layer; $G R$, granule cell layer.

was delivered in a total carrier volume of 2 liters/min for a 1-hr exposure period. The pup then was removed from the testing chamber and was decapitated immediately. Preparation of the tissue for autoradiography followed standard procedures of the Sokoloff method (Kennedy et al., 1975; Sharp et al., 1975, 1977). The tissue sections were subsequently stained with cresyl violet for histological correlation with the autoradiographs. Photographic enlargement of the autoradiographs and corresponding histology permitted superpositioning of the olfactory bulb laminae upon the autoradiographs. These were em- ployed for laminar and topographical analyses of the 2DG patterns.

The cross-laminar distributions of 2DG were analyzed with reflectance densitometry. Photographic enlargements $(\times 50)$ of the autoradiographs were scanned with a small aperture $(2-\mathrm{mm})$ reflectance densitometry probe (Mechanical Technology Inc. Fotonic Sensor). The densities were plotted graphically to assess the relative amount of 2DG uptake within the laminae of the olfactory bulb.

Computer analysis of autoradiographs. Autoradi- 
ographs from sections typical of a given age or treatment condition also were analyzed with a computerized image analysis system (Image Processing System, Drexel University/University of Pennsylvania). The procedure for 2DG image analysis has been described previously (Goochee et al., 1980). Briefly, the sample autoradiograph was scanned optically and the transmitted light was converted to an 8-bit gray level for each of the pixels within the $320 \times 240$ pixel array. This information was digitized and stored by the computer for analysis. The grey scale value for each pixel was normalized and converted to a value equal to the relative optical density of that pixel. Thus, a histogram representing the frequency of optical density units was constructed for each scan. Since we wished to determine the topographical distribution of 2DG foci of high uptake, we partitioned the array of optical densities into four levels which were coded with the computer as colors on the digitized image. The cutoff for the highest densities was chosen arbitrarily as 25 optical density units above the median optical density and was typically in the 90th percentile. The second cutoff was at the 60th percentile, the third was at the 25 th percentile, and the final one was at 0 . This analysis provided a digitized image in which four levels of density (i.e., 2DG uptake) were identified and could be compared with the original autoradiograph to confirm the areas of highest 2DG uptake.
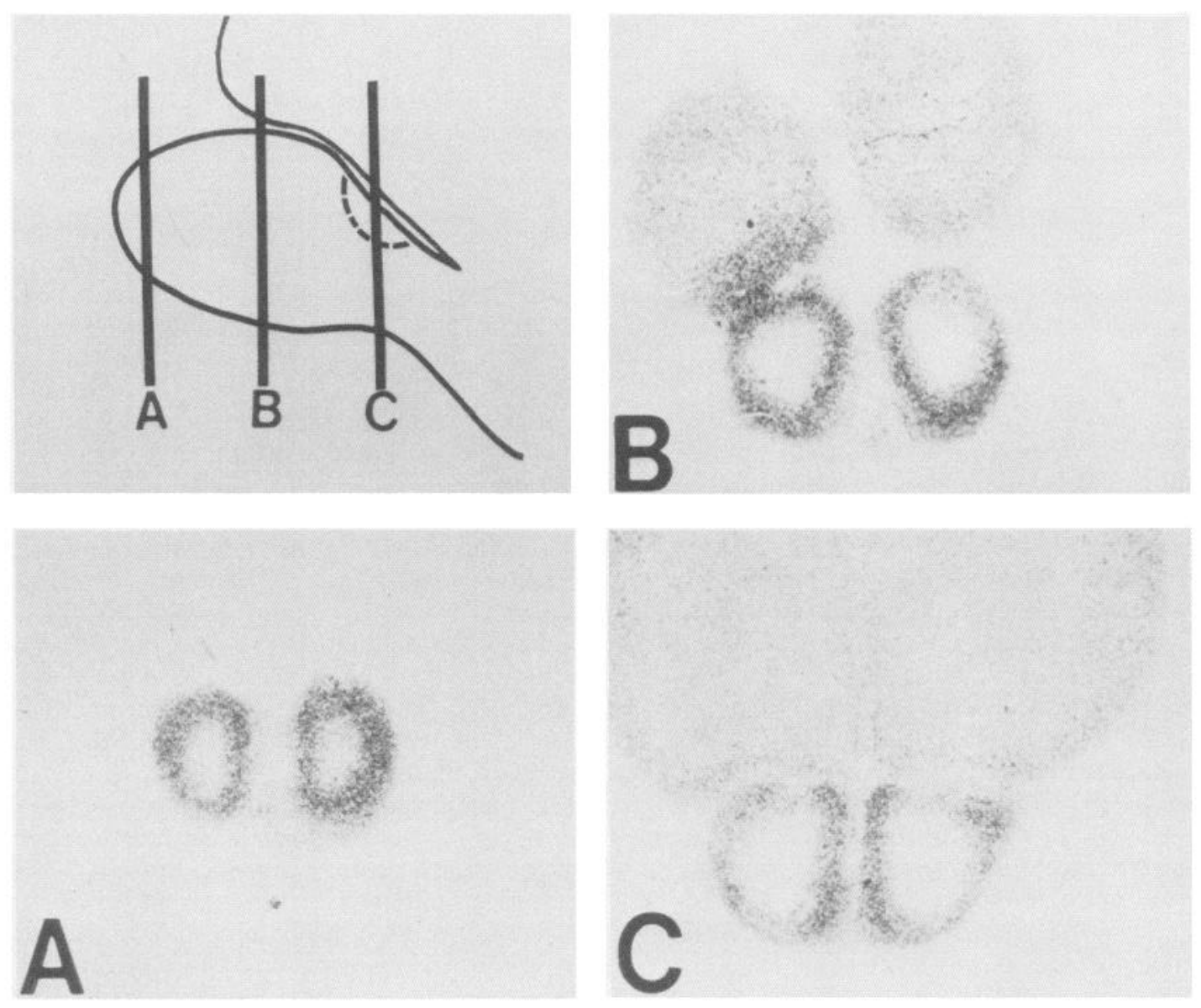

It should be emphasized (cf., Kennedy et al., 1975; Sharp, 1976; Sharp et al., 1977; Proshansky et al., 1980) that these measurements do not constitute a quantitative determination of $2 \mathrm{DG}$ uptake. Rather, they provide a means of comparing the relative amount of $2 \mathrm{DG}$ accumulation within a single animal.

Suckling animals. Two pups from each of the age groups ( 0 to 15 days) were tested with $2 \mathrm{DG}$ during suckling behavior. They were deprived of suckling their dam for 12 to $14 \mathrm{hr}$ prior to the test. Following the administration of $2 \mathrm{DG}$, as outlined above, they were held in contact with the nipple of their anesthetized dam (35 $\mathrm{mg} / \mathrm{kg}$ of pentobarbital) until they attached and began suckling. They remained attached for a period of $1 \mathrm{hr}$ and then were decapitated, and their brains were processed for autoradiography as decribed above.

For controls, an additional 2 pups from each group were exposed to nonodorized, pure air following the administration of $2 \mathrm{DG}$. Subsequent treatment and data analyses in these animals followed the procedures outlined above.

Histology. Since the nature of the 2DG procedure precludes optimal cytological preservation, 2 pups from each age group were prepared with routine methods to examine the histological development of the olfactory bulbs. The rats were anesthetized with an intraperitoneal injection of $50 \mathrm{mg} / \mathrm{kg}$ of pentobarbital (Nembutal) prior

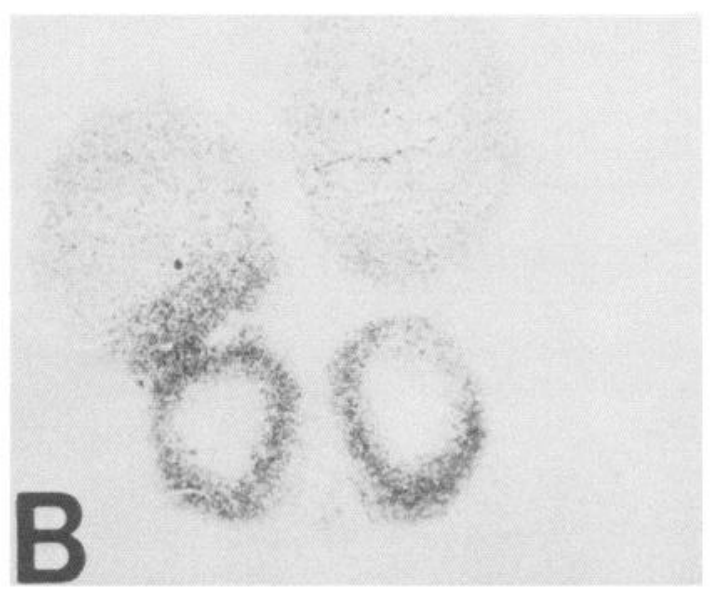

Figure 3. Autoradiographs from the olfactory bulbs of a typical 0-day postnatal rat exposed for 1 hr to pure, nonodorized air. The schematic diagram is a sagittal view of the olfactory bulb indicating the level of the autoradiographs shown in $A, B$, and $C$. 

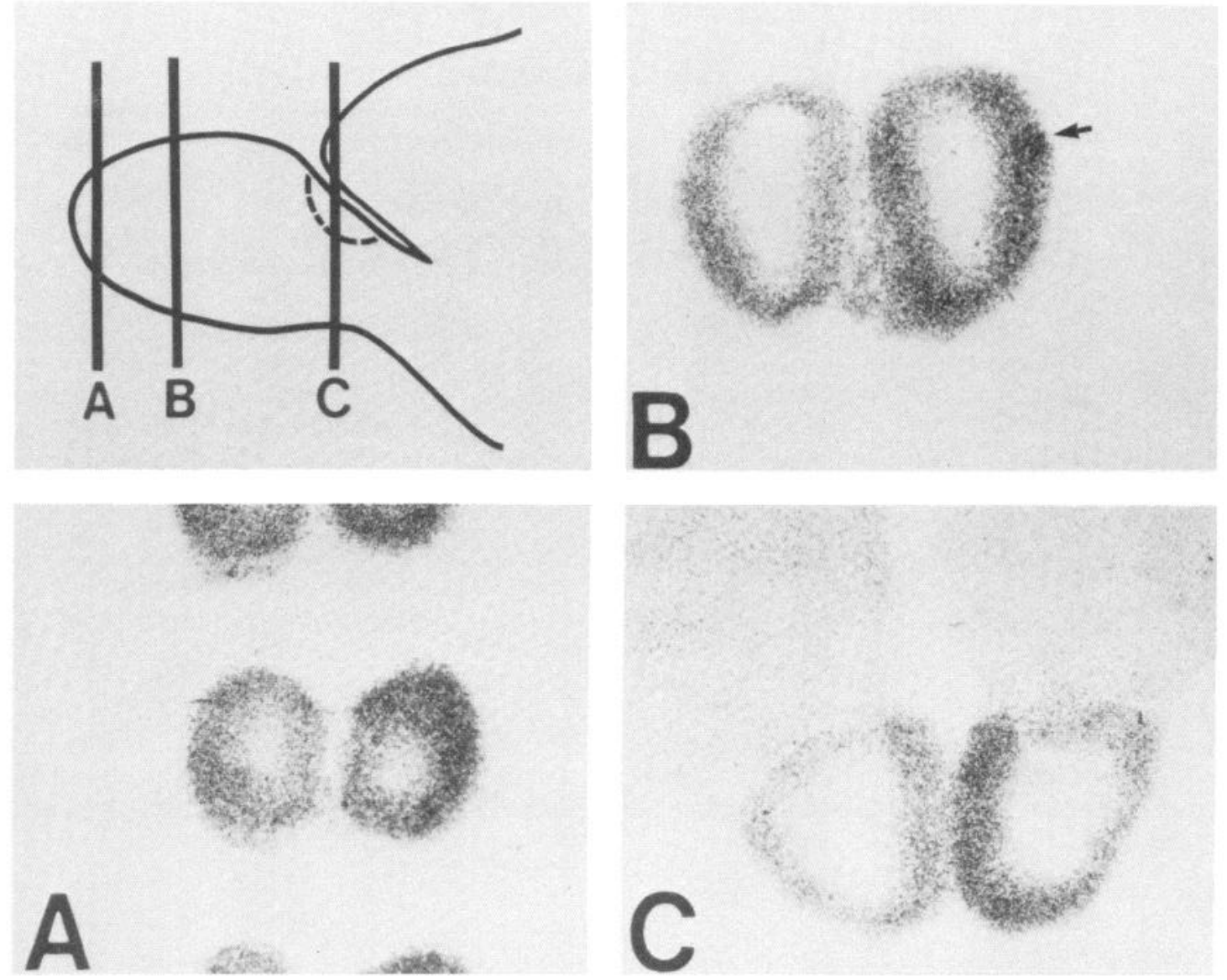

Figure 4. Autoradiographs from the olfactory bulbs of a typical 6-day postnatal rat exposed for $1 \mathrm{hr}$ to a $10^{-1}$ flow dilution of amyl acetate. The schematic diagram is a sagittal view of the olfactory bulbs indicating the level of the autoradiographs shown in $A, B$, and $C$. The arrow indicates the area of focal $2 \mathrm{DG}$ uptake.

to an intracardiac perfusion of $3 \mathrm{ml}$ of $0.9 \% \mathrm{NaCl}$ and 15 $\mathrm{ml}$ of Bouin's solution at room temperature. Routine procedures were followed for obtaining paraffin-embedded, cresyl violet-stained, $10-\mu \mathrm{m}$ sections of the olfactory bulb.

\section{Results}

Mapping with 2-deoxyglucose. Animals at all ages showed evidence of odor-induced 2DG uptake in the olfactory bulbs following exposure to amyl acetate. Autoradiographs typical of a 0-day rat stimulated with amyl acetate are shown in Figure 1. Throughout the rostralcaudal axis of the olfactory bulb, a broad intermediate band of higher 2DG uptake is found. Within this band, there appear two primary variations in $2 \mathrm{DG}$ uptake. First, at some sites, the density appears comparatively light. For example, the medial wall of the left bulb in Figure $1 A$ appears less dense, indicating less $2 D G$ uptake, than elsewhere within the band. The second variation is the presence of comparatively higher levels of 2DG uptake within restricted zones of the band. These are particularly evident in the dorsomedial aspect of both olfactory bulbs in Figure $1 B$ and in the ventromedial aspect in Figure $1 C$.

The laminar pattern of $2 \mathrm{DG}$ uptake in the 0 -day rat was determined by reflectance densitometry as shown in Figure 2 . The outlines of the mitral body layer and the inner border of the olfactory nerve layer were superimposed as white lines upon the autoradiograph of the right bulb shown in Figure $2 A$. This revealed that the broad band of 2DG uptake extended between the olfactory nerve layer and the outer portion of the granule cell layer. Cross-laminar densitometry scans, as illustrated in Figure $2 B$, were made over the autoradiograph. The scan passing over a region of the bulb with relatively high uptake (Fig. $2 B$, scan 1) showed a dramatic increase in density beginning in the outer margin of the olfactory nerve and extending through the glomerular and external plexiform layers (Fig. $2 C$ ). Density decreased somewhat over the mitral body and granule cell layers. The scan through the neighboring region (Fig. $2 B$, scan 2 ) showed a similar laminar pattern but at a lower level of density (Fig. $2 D$ ). These laminar profiles of $2 \mathrm{DG}$ uptake are consistent with the profiles seen in the adult (Sharp et al., 1977; Stewart et al., 1979).

A typical result from a control 0-day rat pup exposed to pure, nonodorized air is illustrated in Figure 3. The intermediate band is present, but there are only slight variations of density within it, and no foci are seen. This is consistent with previous results in the adult (Sharp et al., 1977) and suggests that the intermediate band under these conditions reflects basal levels of metabolic activity independent of odor stimulation.

The intermediate band of $2 \mathrm{DG}$ uptake was present in 
all of the age groups tested. Developmental changes in the nature of $2 \mathrm{DG}$ uptake were recognized as foci or variations within the band, which will be described as follows.

At 3 days postnatal, uptake appeared very similar to that illustrated for 0 days (cf., Figs. 1 and 2). Occasional regions of increased or decreased density were observed within broadly defined quadrants of the bulb. The regions of increased uptake appeared predominantly in the caudomedial portion of the bulb (cf., Fig. $1 B$ ). At 6 days postnatal, sharply circumscribed, dense foci were first seen (Fig. $4 B$, arrow). These foci were present within the intermediate band together with broader variations. At 9 to 12 days postnatal, the numbers of foci (Fig. $5 \mathrm{~A}$, arrow) and of broader variations (Fig. $5 B$, medial wall) increased. The foci also appeared more dense than those previously observed (Fig. 5A, arrow). Between 15 and 21 days postnatal, well defined foci of increased uptake were predominant (Fig. 6). These foci appeared as punctate "dots," either singly (Fig. 6A, arrow) or in "chains" (Fig. $6 C$, medial wall).

In Figure 7 the autoradiographs from a 21-day control rat exposed to pure, nonodorized air may be contrasted with the amyl acetate-elicited pattern seen in Figure 6. Following pure air, the intermediate band of uptake was present, but punctate foci were almost completely absent (see similar finding in a 0-day rat above, Fig. 3).
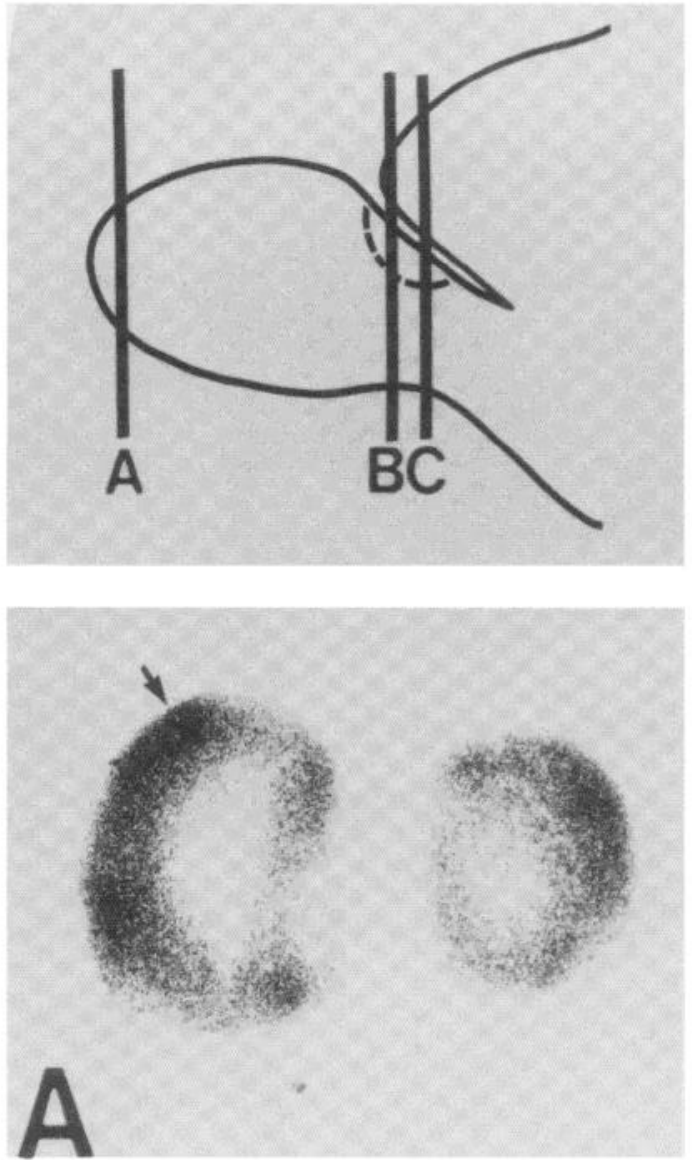

In Figure 8, examples of black and white reproductions of the color-coded computer image analyses performed on autoradiographs from Figure 1 and Figures 3 to 7 are presented. The four density levels illustrated by the four grey levels were determined as described under "Materials and Methods." The highest densities, 90th percentile and above, correspond to the 2DG foci seen in the original autoradiographs. The second highest densities, 60 th to 89 th percentile, typically included the intermediate band of 2DG uptake. The third level of densities, 25th to 59th percentile, usually included transition areas around the borders of the intermediate band. The lowest level of densities, 0 to 24th percentile, included those areas with the least $2 \mathrm{DG}$ uptake, for example, the ventricular core of the bulb.

Utilizing this convention, regions of high 2DG uptake (high optical density) within the intermediate band were easily identified by image analysis, and the general patterns of 2DG uptake, described above, were confirmed. For example, in Figure $8 A$, a comparatively broad area of uptake is seen dorsomedially in the right bulb (cf., Figs. $1 B$ and 2 ). This uptake of a 0 -day rat stimulated with amyl acetate contrasts with the scan of a 0-day rat exposed to pure air shown in Figure $8 B$. In the latter case, the intermediate band appears homogeneous with the exception of a slight focus in the ventromedial aspect of the bulb (cf., Fig. $3 C$ ). In Figure $8, C$ and $D$, the
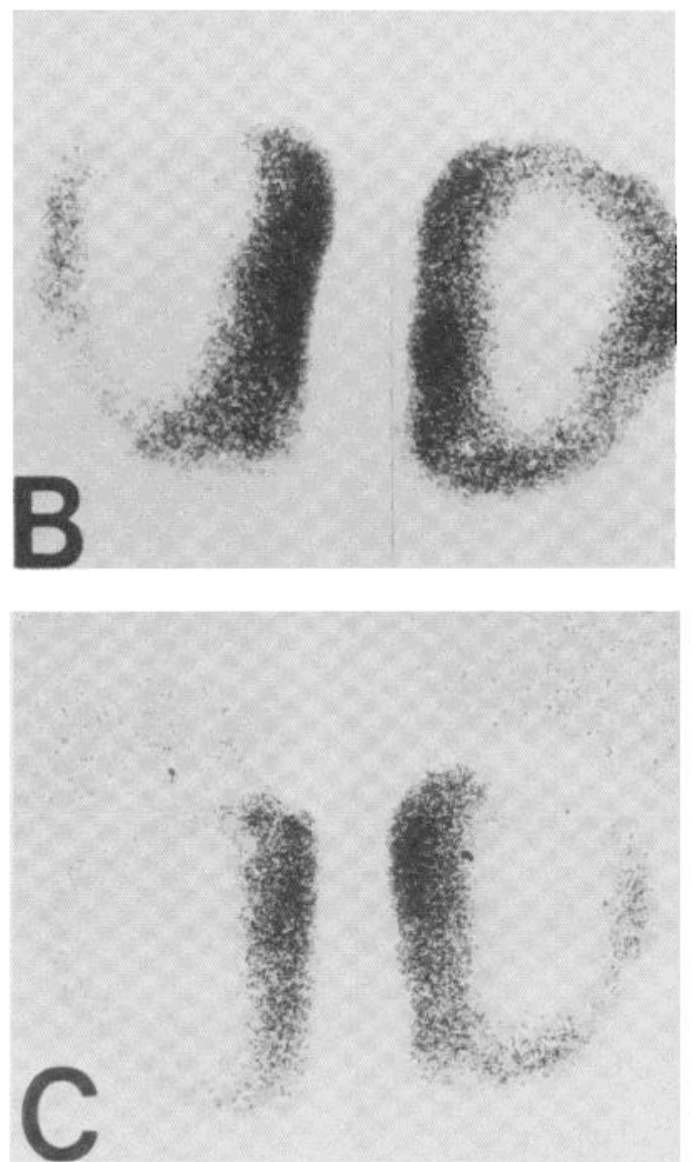

Figure 5. Autoradiographs from the olfactory bulbs of a typical 12-day postnatal rat exposed for $1 \mathrm{hr}$ to a $10^{-1}$ flow dilution of amyl acetate. The schematic diagram is a sagittal view of the olfactory bulbs indicating the level of the autoradiographs shown in $A, B$, and $C$. The arrow indicates the area of increased 2DG uptake. 

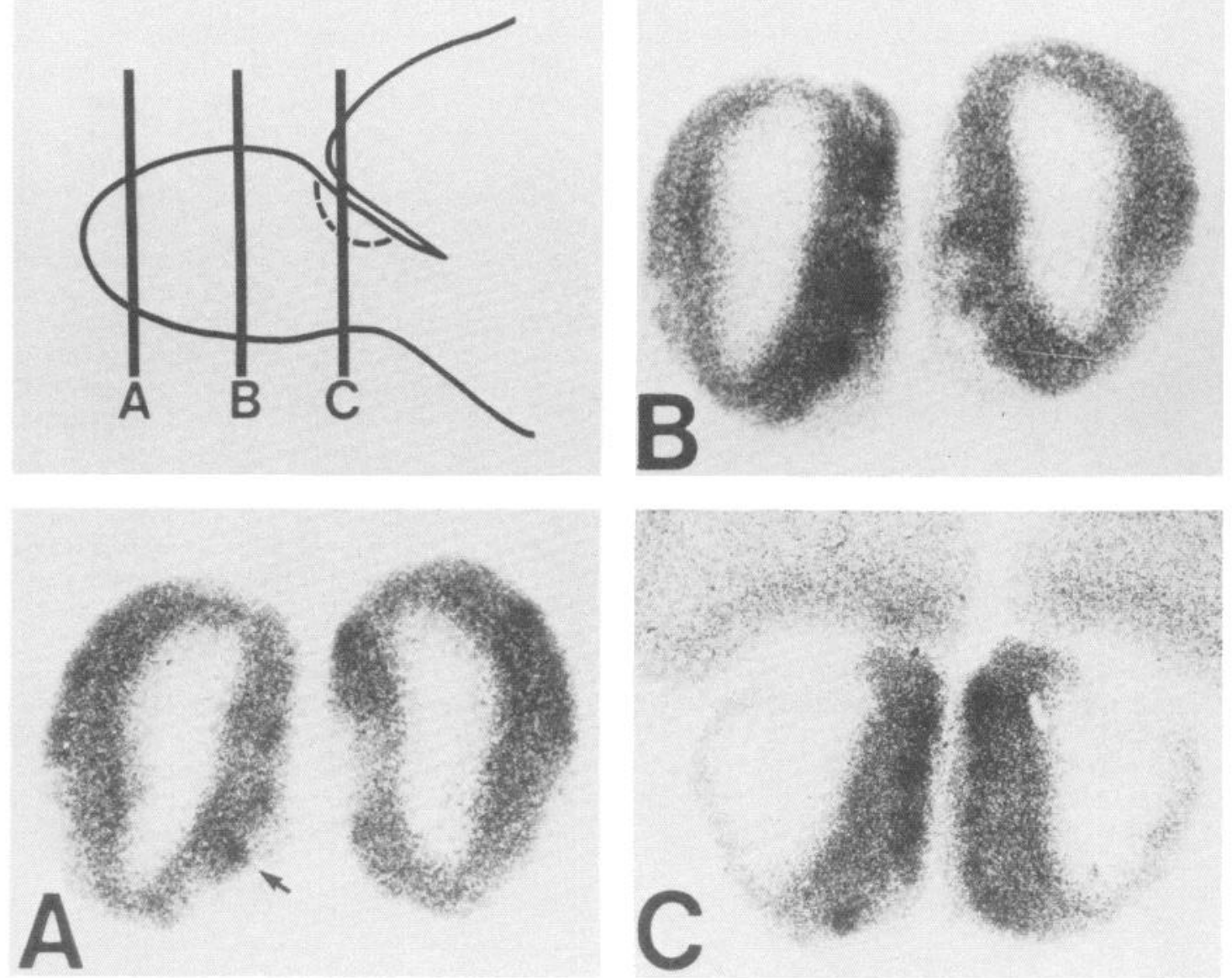

Figure 6. Autoradiographs from the olfactory bulbs of a typical 21-day postnatal rat exposed for $1 \mathrm{hr}$ to a $10^{-1}$ flow dilution of amyl acetate. The schematic diagram is a sagittal view of the olfactory bulbs indicating the level of the autoradiographs shown in $A, B$, and $C$. The arrow indicates focal 2 DG uptake.

appearance of sharp focal uptake at 6 days and the proliferation of uptake by 12 days is exemplified (cf., Figs. $4 B$ and $5 A$, respectively). In Figure $8 E$, the numerous punctate foci elicited by amyl acetate stimulation in the 21-day rat are illustrated (cf., Fig. $6 A$ ). In contrast, Figure $8 \mathrm{~F}$ emphasizes the relatively homogeneous composition of the intermediate band in a 21-day rat exposed to pure, nonodorized air (cf., Fig. $7 A$ ).

Topographical distribution. The topographical distribution of foci within the glomerular layer exhibited developmental changes. In the youngest rats ( $\leq 6$ days), 2 DG foci were found predominantly in the caudomedial aspect of the bulb (cf., Figs. 1 and 4). At these ages, the glomerular layer (GL) was not yet fully differentiated (see below) and the areas of higher 2DG uptake were limited to those segments which appeared most mature. Subsequent to 6 days, there was a proliferation of foci (see above) which included the appearance of foci in the rostrolateral domain of the bulb (cf., Fig. 5). Many of these foci appeared as "chains" along a segment of the GL (cf., Fig. 5B, medial wall). The foci became less numerous around 15 to 21 days and were confined within rostrolateral and caudomedial "domains" (e.g., Fig. 6).

The patterns of $2 \mathrm{DG}$ densities following exposure to pure, nonodorized air clearly differed from the patterns elicited by amyl acetate. Across all of the ages, focal densities were observed infrequently and did not exhibit clustering into specific domains (cf., Figs. 3 and 7).

Suckling rats. All of the neonatal rat pups tested with 2DG during suckling showed focal 2DG uptake. This typically occurred in a specific region of the olfactory bulb which did not exhibit increased uptake following pure air or amyl acetate exposure. Typical examples from $0-, 6-$, and 12-day postnatal rats are shown in Figure 9. In the autoradiographs (Fig. 9, $A, C$, and $E$ ), a bilateral density is seen in the caudal dorsomedial aspect of the olfactory bulb (see arrows). These densities are enhanced in the corresponding computer image analyses (Figs. 9, B, D, and $F$ ). Other areas of increased 2DG uptake also were observed in the suckling animals (Fig. $9, A$, medial wall, and $C$ and $E$, lateral walls) but these did not occur with the regularity of the caudal dorsomedial focus.

The correlation of these observations with the histology of the bulb is shown in Figure 10. In figure $10 \mathrm{~A}$, the outline of the area of increased density, as seen in the autoradiograph of Figure $9 E$, has been superimposed as a white line (arrow) on the corresponding histological section. As can be seen, the 2DG focus is localized over a distinctive part of the glomerular layer, characterized by one or several large and irregular glomeruli; we refer to this as a modified glomerular complex (MGC). The 
MGC lies adjacent to the accessory olfactory bulb (AOB) and is usually distinct from the main glomerular sheet. Superimposing the outline of the MGC upon the autoradiograph as in Figure $10 B$ shows that the 2DG focus falls precisely on the MGC. The correlation of the caudal dorsomedial 2DG focus with the MGC was confirmed at all ages tested during suckling.

Histological analysis. As described under "Materials and Methods," a series of olfactory bulbs was prepared for better characterization of the histological development of the bulb. The results of this series for the main olfactory bulb are summarized by the typical sections shown in Figure 11. In general, there was progression, spanning the first 21 postnatal days, from poorly differentiated laminae toward the distinctive lamination characteristic of the mature mammalian olfactory bulb. The laminae differed in certain respects during development. Of special interest was the demarcation of individual glomeruli by their ring of periglomerular cells around 6 days postnatal (Fig. $11 \mathrm{C}$ ). Also, the number and diameter of glomeruli increased throughout the 21-day period. These changes are emphasized in Figure 12, which shows, at higher magnification, the regions indicated by boxes in Figure 11, $A, C$, and $H$. At 0 days, individual glomeruli cannot be identified (Fig. 12A). By 6 days (Fig. 12B), several small glomeruli may be discerned, and in some cases, their complete cross-sectional circumference is well defined by periglomerular cells (contrast with 3 days in Fig. $11 B$ which shows only partial periglomerular cell borders). At 21 days (Fig. $12 C$ ), the glomeruli appear adult-like and have increased in diameter significantly.

Further laminar changes illustrated in Figure 11 include the differentiation of the internal and external zones of the external plexiform layer (EPL). This change begins around 6 to 9 days and an adult pattern is evident by 12 to 15 days. The mitral body layer (MBL) is the only lamina which appears to decrease in thickness during development. As seen in Figure $11 A$, at 0 days, the MBL appears as a thick band comprised of several layers of large perikarya. During the ensuing days, this band decreases in width to the single layer of perikarya typical of the adult. Few changes are apparent in the MBL after 12 days. The internal plexiform layer, interposed between the MBL and the granule cell layer (GRL), emerges as a distinct layer at 6 days and appears characteristic of the adult by 18 days. Finally, the GRL appears as a field of scattered perikarya at 0 to 3 days; around 6 days, it begins to slow clustering of cell bodies. By 15 days, islets of granule cells, typical of the adult, are present.

Typical histological sections containing the MGC of rats at 0,6 , and 12 days postnatal are shown in Figure 13 (see arrows). In Figure $13 A$, a low magnification view shows the topography of the MGC in a 0-day rat. At higher magnification in Figure 13B, additional details are
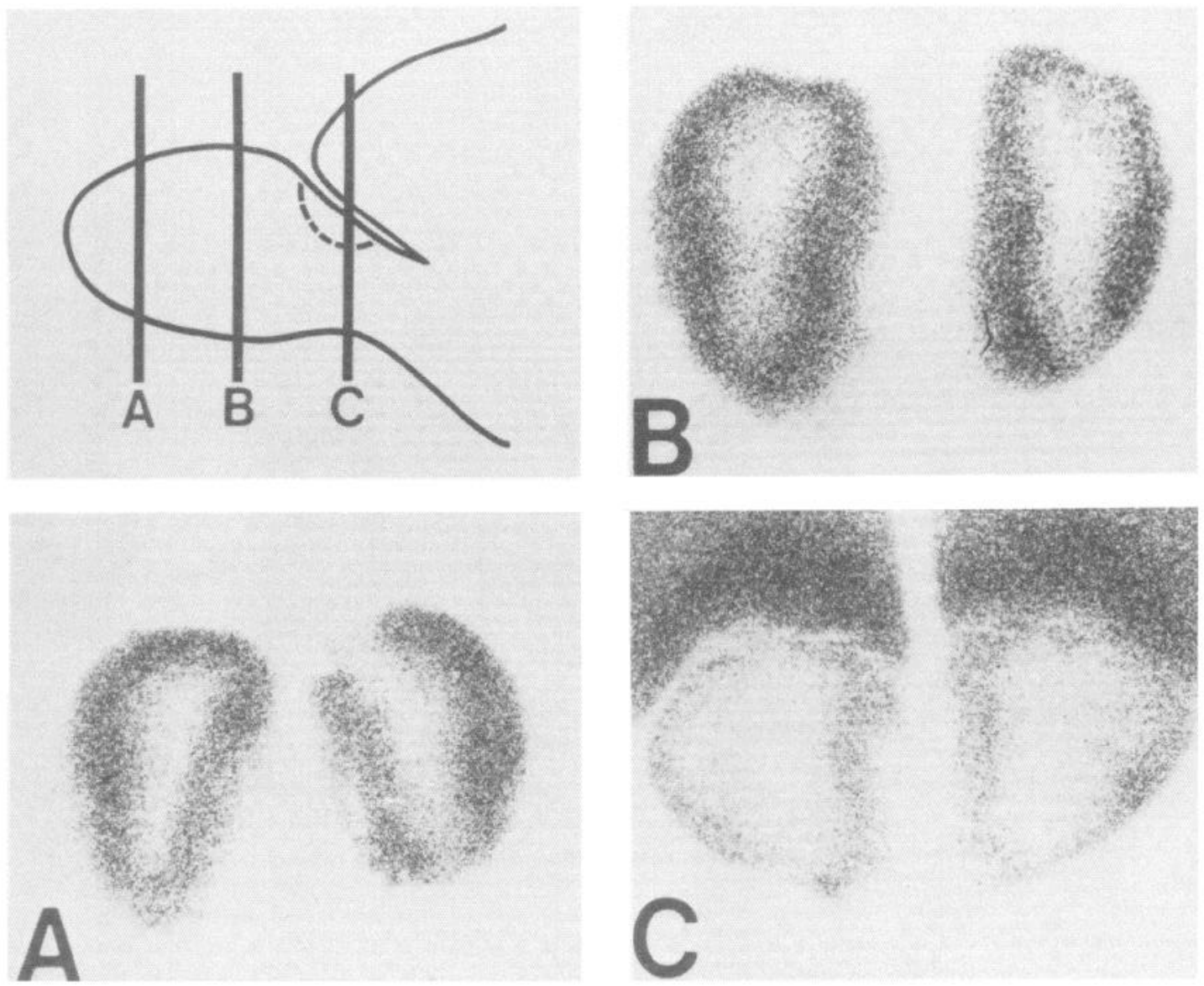

Figure 7. Autoradiographs from the olfactory bulbs of a typical 21-day postnatal rat exposed for 1 hr to pure, nonodorized air. The schematic diagram is a sagittal view of the olfactory bulbs indicating the level of the autoradiographs shown in $A, B$, and $C$. 

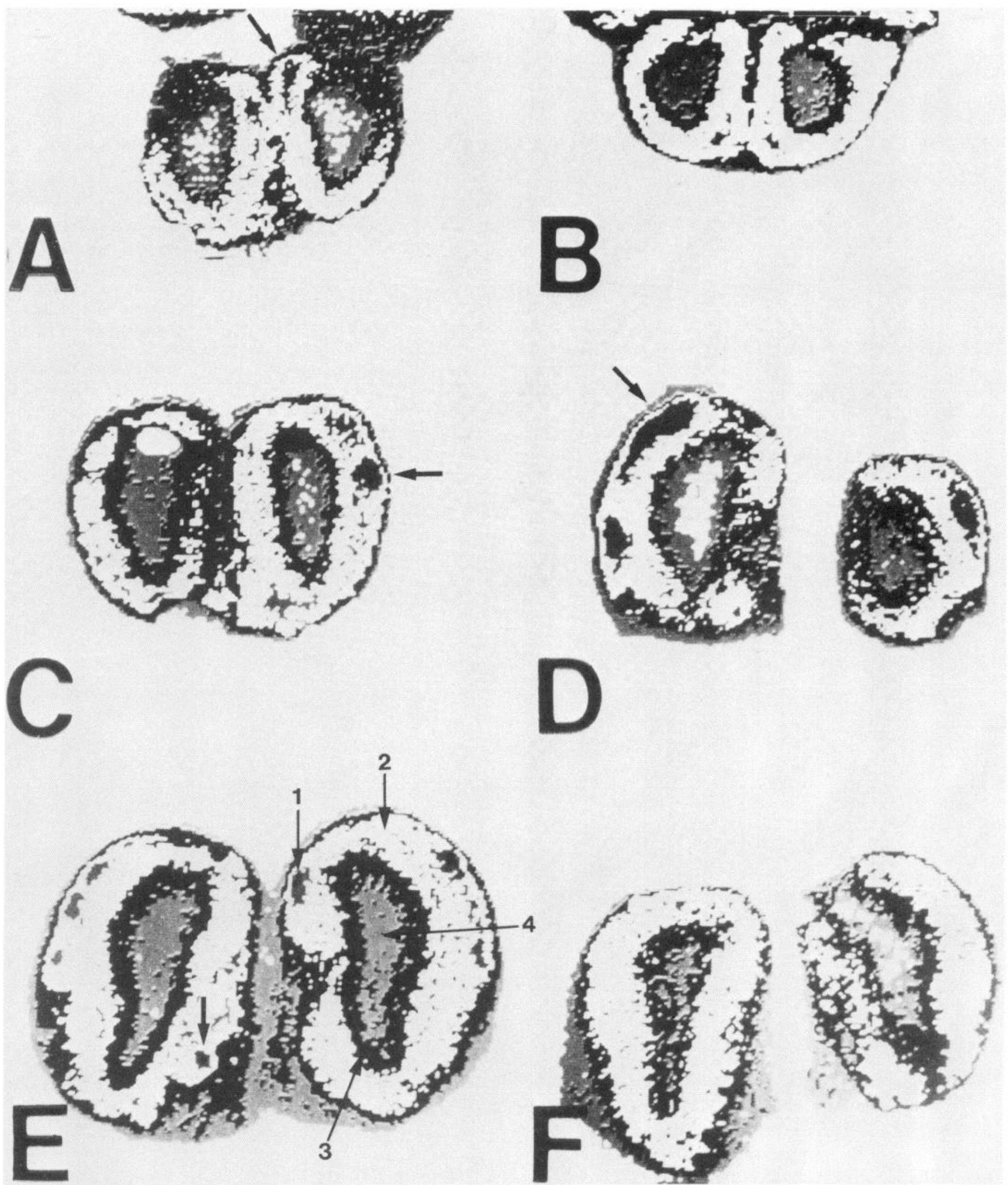

Figure 8. Computer-assisted density scans of autoradiographs from Figures 1 to 7 . A, 0-day rat exposed to $10^{-1}$ amyl acetate (cf., Figs. $1 B$ and 2); $B, 0$-day rat exposed to nonodorized, pure air (cf., Fig. $3 C$ ); $C$, 6-day rat exposed to $10^{-1}$ amyl acetate (cf., Fig. $4 B$ ); $D, 12$-day rat exposed to $10^{-1}$ amyl acetate (cf., Fig. $5 A$ ); $E$, 21-day rat exposed to $10^{-1}$ amyl acetate (cf., Fig. $6 A$ ); $F, 21$-day rat exposed to nonodorized, pure air (cf., Fig. 7A). The scans are black and white reproductions of color photographs illustrating the four levels of density which are proportional to 2DG uptake. For orientation, the density scale, as defined under "Materials and Methods" is indicated by the numbered arrows in $E$, proceeding from the highest density (1) to the lowest density (4). Slight variations in the grey scales (for example, in the core of the two bulbs in $B$ ), do not reflect different densities but, rather, the conversion of the color photographs to black and white. The unlabeled arrows indicate computer-identified densities previously observed as typical areas of increased 2DG uptake in Figures 1 and 4 to 6. 


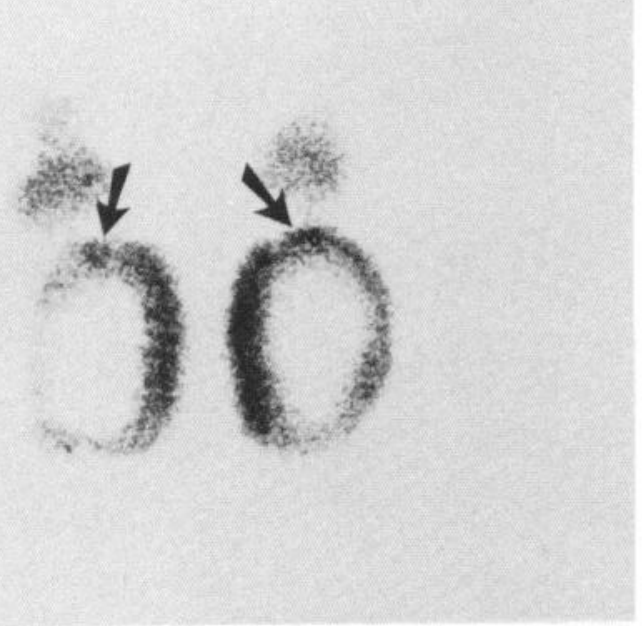

\section{A}
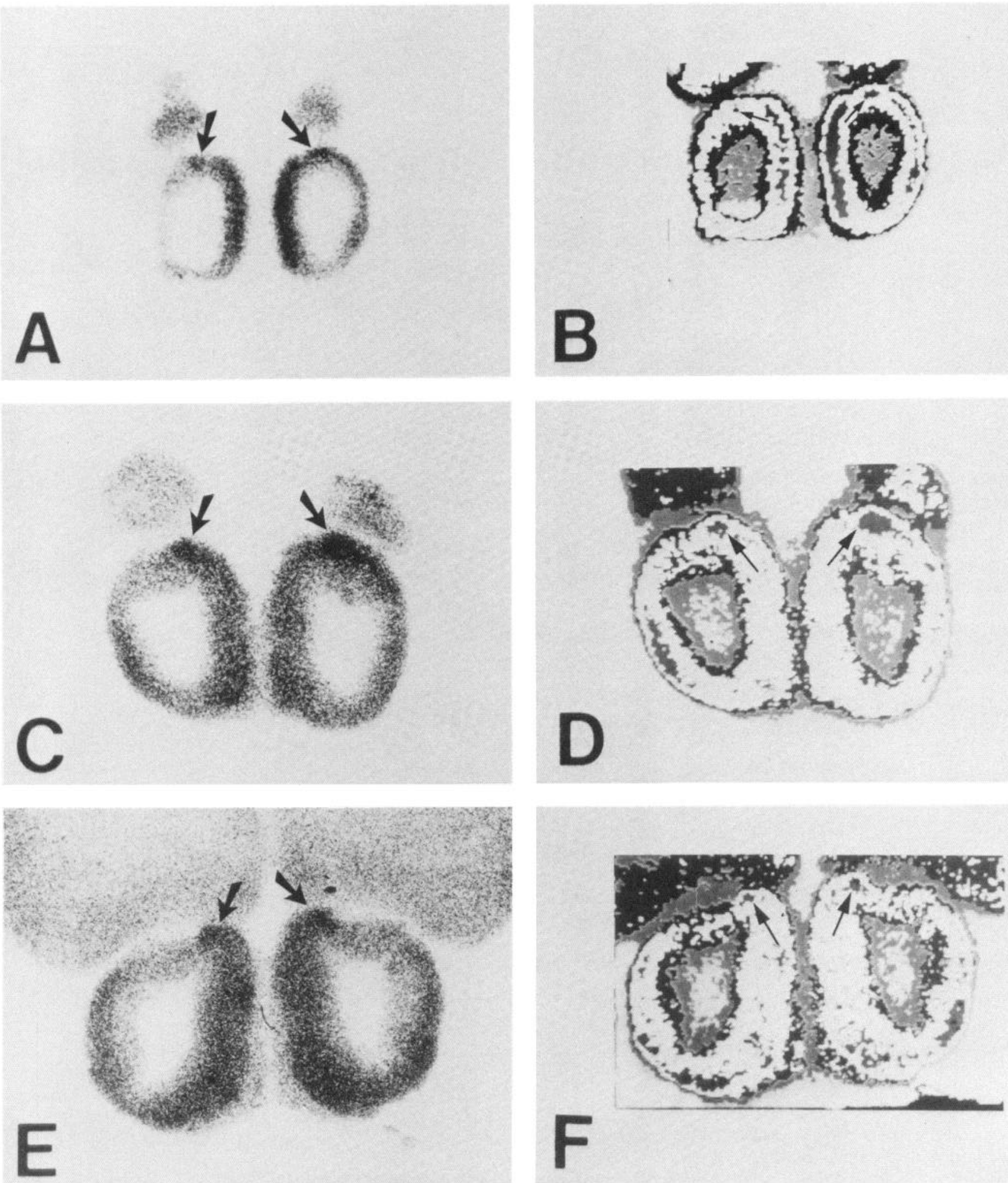

Figure 9. Autoradiographs and corresponding computer scans from the olfactory bulbs of rats following suckling behavior. $A$ and $B, 0$ days postnatal; $C$ and $D, 6$ days postnatal; $E$ and $F, 12$ days postnatal. The arrows indicate the caudal dorsomedial $2 D G$ focus in the autoradiographs and corresponding computer density scans.

apparent. The MGC lies at the edge of the most dorsal extension of the MBL along the medial wall of the main olfactory bulb. At its lateral border, the MGC is segregated from the AOB by scattered small cell bodies. In the 6-day rat (Fig. 13, $C$ and $D$ ), the modified glomerulus is demarcated distinctly by the surrounding border of periglomerular cells. The segregation of this glomerulus from the main glomerular sheet is evident from the 

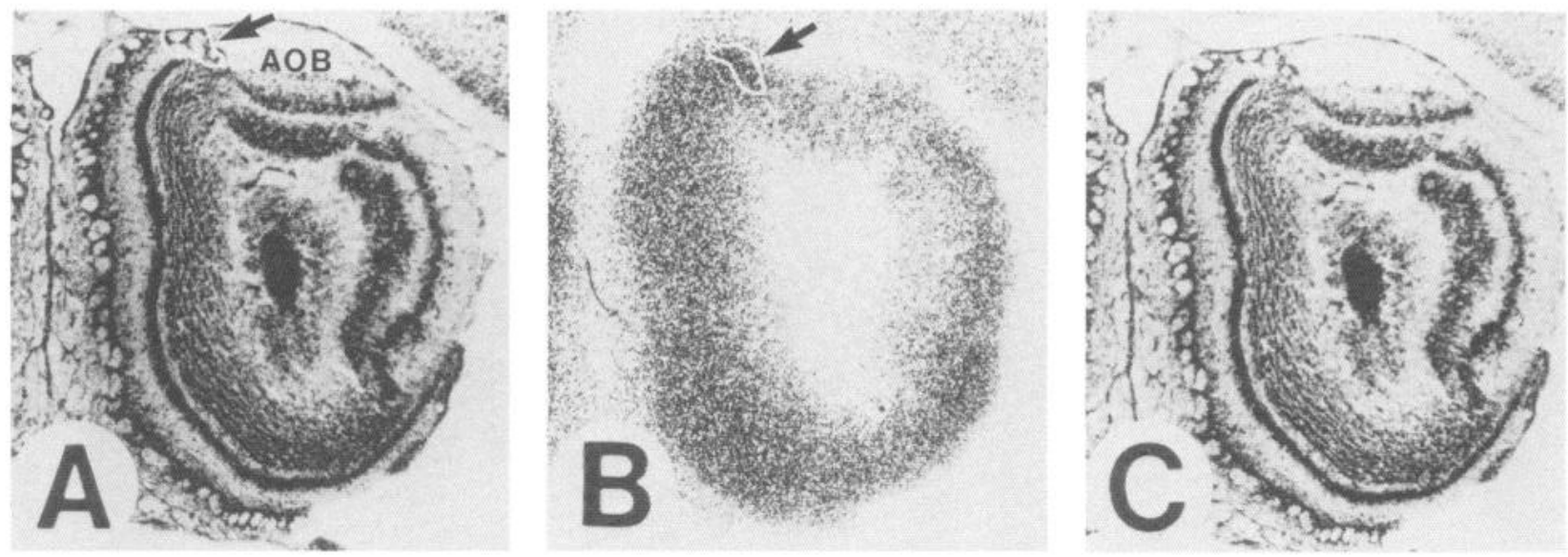

Figure 10. Histological correlation of the right olfactory bulb shown in the autoradiograph in Figure $9 E$. In $A$, the outline of the 2DG density (cf., Fig. 9, $E$ and $F$ ) is superimposed as a white line upon the corresponding histology (see arrow). In $B$, the outline of the MGC, as seen in $C$, is superimposed as a white line upon the autoradiograph (see arrow). $A O B$, accessory olfactory bulb.

cluster of intermediate size perikarya. At 12 days (Fig. $13, E$ and $F$; cf., Fig. 10 ), a small cluster of glomeruli comprising the MGC is easily identified. The differentiation from the AOB and main glomerular layer is apparent. In Figure $13 F$, it may be seen that the MGC is isolated by a mixed collection of small and intermediate perikarya. This observation further serves to contrast the MGC with the glomeruli of the AOB which, at this age, are still relatively poorly differentiated. Since the MGC may be readily identified in the 0 -day rat, it appears that it matures earlier than other glomerular regions.

\section{Discussion}

The results will be discussed first in relation to the properties of odor-induced 2DG uptake in the bulb and their histological correlates and secondly in relation to the identification of the MGC.

There is general agreement that the uptake of $2 \mathrm{DG}$ observed with the Sokoloff method is associated with sites of increased neuronal activity (Greer et al., 1981a; Schwartz et al., 1979; Mata et al., 1980). Our previous studies, as well as those of others, in the mammalian olfactory system support this interpretation (Sharp et al., 1977; Stewart et al., 1979; Jourdan et al., 1980; Greer et al., 1981a, b). These studies established that 2DG foci are localized in the GL, where the terminals of the olfactory receptor cells are found. This has implied that receptor cell activation contributes significantly to glomerular 2DG uptake. This interpretation, first based on results with the standard Sokoloff method, has been confirmed recently with high resolution methods at the cellular level (Lancet et al., 1982). These interpretations are consistent with the present results. Based on this conclusion, the present findings thus provide evidence for functional activity in both receptor cell terminals and their postsynaptic targets in the olfactory bulb within the first few hours following birth. These results extend the findings of Astic and Saucier (1982), who reported odor-induced 2DG uptake in the olfactory bulbs of rats at 1 day postnatal.

There are several clear differences in comparing the characteristics of $2 D G$ uptake in the 0 -day rat with those of the adult. To begin with, regions of uptake appear less dense and punctate in the 0 -day olfactory bulb. There is, in particular, an absence of the sharply defined, high density foci over the glomeruli that are characteristic of the adult. This may be correlated with our observation that individual glomeruli are poorly differentiated in the 0 - to 3-day rat. It is interesting to note that Singh and Nathaniel (1978) reported some degree of cytological immaturity of mitral cells (e.g., scarce, rough endoplasmic reticulum) at birth. Also, the periglomerular cells have not yet completed differentiation and migrated to the glomerular layer (Altman, 1966), where they contribute to the definition of individual glomeruli as seen with light microscopy. Finally, Hinds and Hinds (1976a, b) reported that, although synaptic density increases most rapidly in the glomeruli, axodendritic contacts are most numerous at birth, while dendrodendritic synapses lag several days behind. This observation implies that the intra- and interglomerular inhibitory modulation of afferent input to the glomeruli (Lancet et al., 1982) may not be functionally mature at birth.

A related observation is that, for the same concentration of amyl acetate ( $10^{-1}$ flow dilution), the numbers of 2DG foci in the 0-day rat are much less than typically observed in the adult. The proportion of the glomerular sheet occupied by increased densities in the 0-day rat appears roughly equivalent to that previously reported for a $10^{-3}$ flow dilution in the adult (Stewart et al., 1979). Behavioral data also have suggested a low sensitivity to odors in the newborn. Alberts and May (1980a, b), using respiratory polypnea to assess olfactory sensitivity, demonstrated that 1-day postnatal rats have the ability to detect only a $10^{-2}$ concentration of amyl acetate; the detection ability increased approximately 2 -fold during the following 7 days. Employing other odorants, Astic and Saucier (1982) also reported little 2DG uptake in the olfactory bulbs of 1-day postnatal rats, although uptake increased at the next two ages tested, 9 and 21 days postnatal. In the previously cited ultrastructural studies of the mouse olfactory bulb, the number of axodendritic synapses found in the glomerular layer of the neonate represented only $1 \%$ of the number found in the 21-day animal. In accord with this observation, the numbers of mature olfactory receptor axons entering the glomeruli 

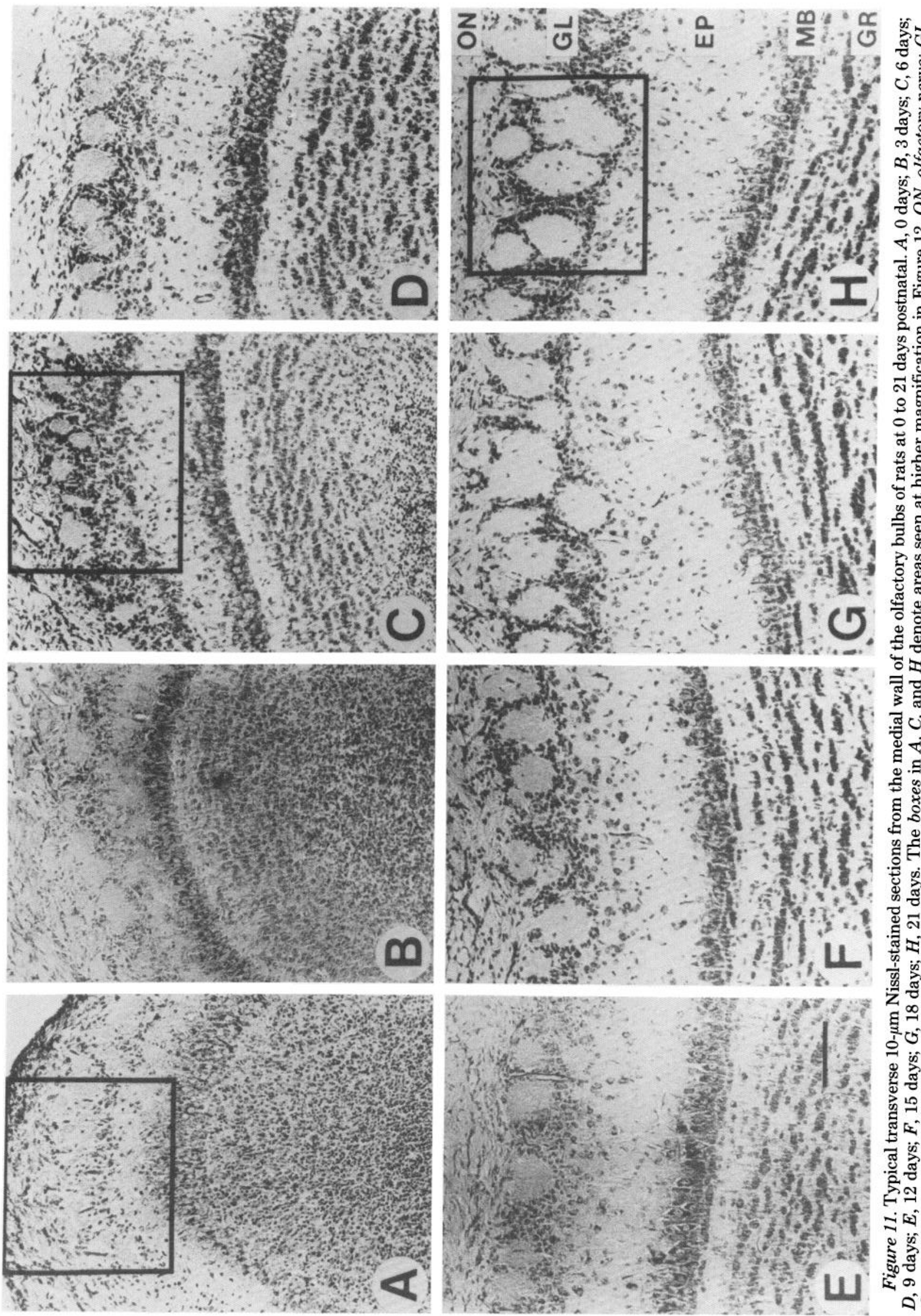
ন 음 कू

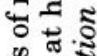
응 แ 政 สี 용 焉 노요 สี สี 哥 छิن . $\Xi$ 赵记 응 $4 \%$ 늘

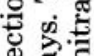
要 สำ

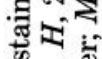
娄密

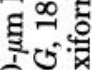
is 象 㝵 10 政 \pm is 0 क्षे ริํㅝ - 100

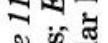
5ิำ \% व. 

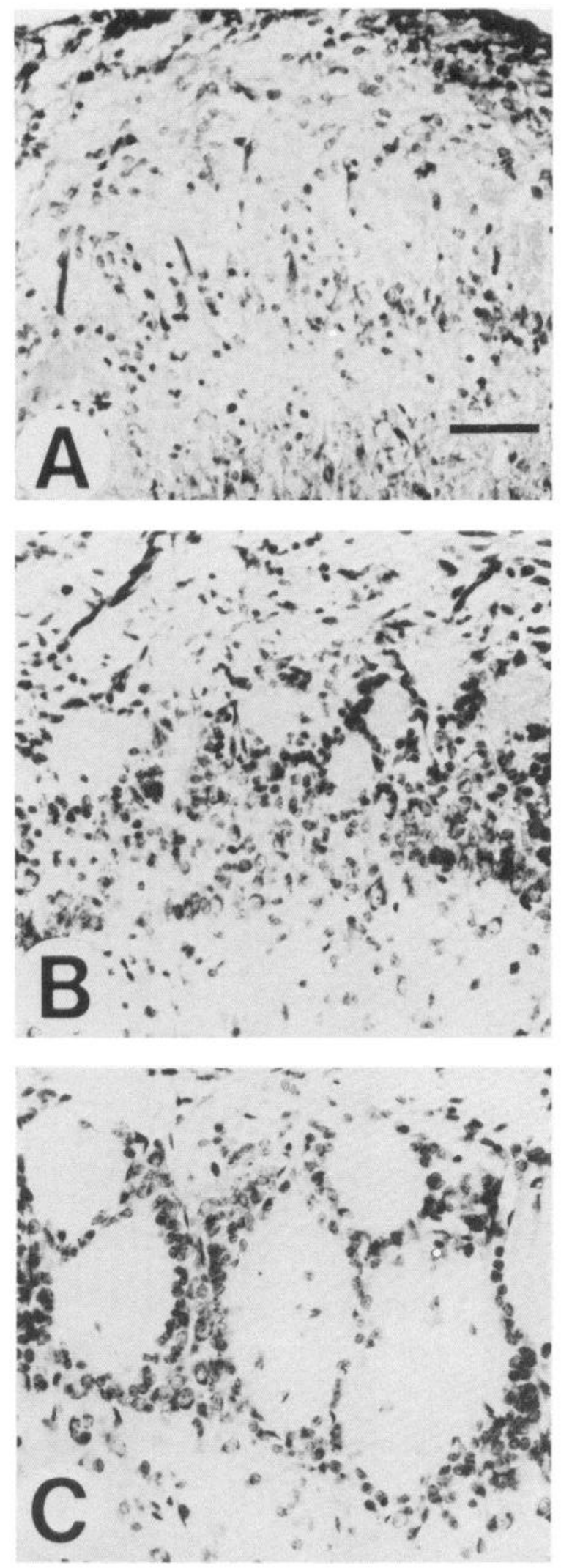

Figure 12. Photomicrographs illustrating glomerular development in the areas demarcated by boxes in Figure 11. $A, 0$ days; $B, 6$ days; $C, 21$ days. Calibration bar $(A), 50 \mu \mathrm{m}$. of the neonate are notably fewer than in the adult (MontiGraziadei et al., 1980). Thus, it would appear that the relatively low number of $2 \mathrm{DG}$ foci found in the 0 -day rat may reflect a comparatively low number of excitatory afferent inputs to the bulb.

A general observation of some interest is the presence of asymmetries in $2 \mathrm{DG}$ uptake in comparing the olfactory bulbs of individual rats (cf., Figs. 3, 4, and 5). These asymmetries appear similar to those previously noted in adult rats stimulated under comparable experimental conditions (Stewart et al., 1979). This makes it unlikely that $2 \mathrm{DG}$ asymmetries reflect differences in the rates of maturation of the olfactory epithelium or olfactory bulbs on one side or the other. In the adult, it was suggested that these asymmetries are due to changes in the patencies of the nasal passageways which vary cyclically from one side of the nose to the other over periods of 1 to $2 \mathrm{hr}$ (Stewart et al., 1979; Bojsen-Moller and Fahrenkrug, 1971). Alternatively, there may be some variability in the rostral-caudal level of the sections through the two olfactory bulbs. Similar explanations may apply to the data reported for the neonatal rat.

A point of some importance is the observation that the topographical distribution of $2 \mathrm{DG}$ foci in the glomerular layer of the neonate, following amyl acetate stimulation, includes domains similar to those found in the adult; these are the rostrolateral and caudomedial aspects of the bulb (Stewart et al., 1979). In the youngest rats ( 0 to 6 days), the $2 \mathrm{DG}$ uptake appears predominantly in the caudomedial zone. This suggests that the innervation of the bulb by receptor cells which respond to amyl acetate first occurs in the caudomedial part of the bulb. This observation may be related to the recent report of early maturation of the mitral cell projection from the caudomedial division of the olfactory bulb to the olfactory cortex (Grafe and Leonard, 1980).

During the ensuing 21 days of development, the nature of amyl acetate-induced 2DG uptake and its histological correlates appears to progress through several important changes which may be summarized as follows:

1. At 3 days, the characteristics described above for the 0 -day rat also generally apply. The $2 \mathrm{DG}$ patterns remain indistinct as are the olfactory bulb glomeruli as seen in histological sections.

2. The 6-day rat is distinguished by the first appearance of sharp foci similar to those found in the adult. At this age, the glomeruli also first appear well demarcated. Also, the EPL has increased in thickness and granule cells have begun to form islets. It is interesting to note from previous literature that it is also around this age when electrophysiological techniques reveal inhibitory activity (Math and Davrainville, 1980a, b). Also, at this age, there are significant increases in the total number of reciprocal synapses in the glomerular and external plexiform laminae (Hinds and Hinds, 1976a, b).

3. At 9 to 12 days, the $2 \mathrm{DG}$ foci, which previously were located mostly within the caudal-medial aspect of the bulb, spread to the rostral-lateral quadrant. Thus, there is a significant increase in the total amount of odor-induced 2DG uptake. There is also 

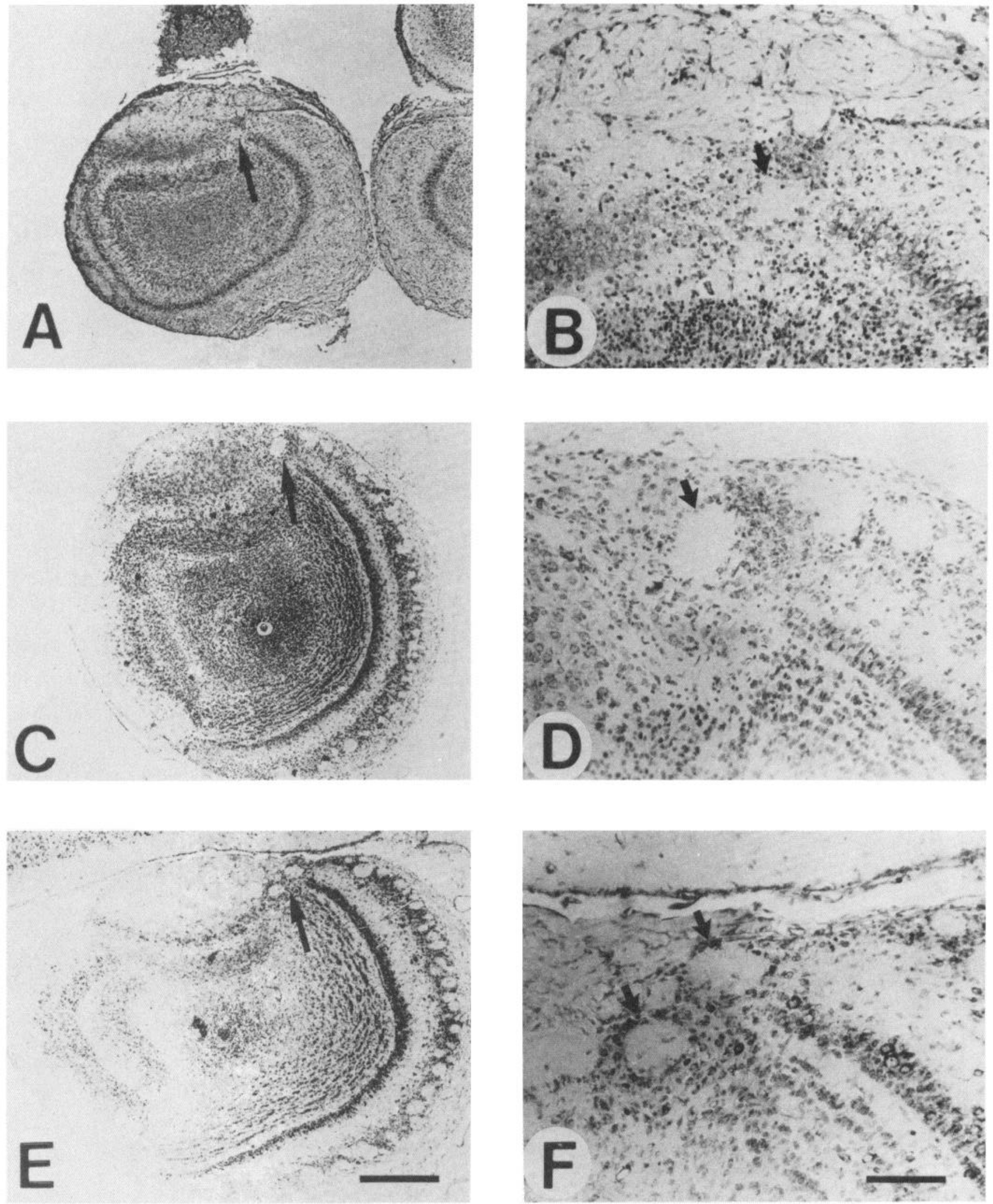

Figure 13. Photomicrographs illustrating the typical morphology of the MGC. $A, 0$ days postnatal; $B$, higher magnification of the MGC seen in $A ; C$, 6 days postnatal; $D$, higher magnification of the MGC seen in $C$; $E$, 12 days postnatal; $F$, higher magnification of the MGC seen in E. Calibration bars: $E, 350 \mu \mathrm{m}, F, 85 \mu \mathrm{m}$. 
a thickening of the EPL and some thinning of the MBL. The glomeruli continue to increase in diameter and definition.

4. At 15 to 21 days, the focal $2 D G$ patterns consolidate into the domains characteristic of the adult. The development of the histological laminae toward the adult size continues, but there is little additional differentiation apparent at the level of the light microscope.

Modified glomerular complex. In the modified glomerular complex (MGC), the nature of 2DG uptake and its histological correlates differs in several respects from that just described for the main olfactory bulb. 'The presence of restricted foci of $2 \mathrm{DG}$ in the MGC during suckling behavior was reported previously in 9- to 12-day rats (Teicher et al., 1980). The present report is the first to identify focal uptake in this region within a few hours of birth. This odor-induced uptake does not appear to be associated with the AOB or the main bulb glomerular sheet. Rather, uptake is restricted to a small group or complex of glomeruli separated from the AOB by a collection of small and medium size cell bodies and from the main glomerular lamina by cell bodies and undifferentiated areas of neuropil. In striking contrast to the relatively indistinct glomeruli of the main bulb, the MGC is easily identified in histological sections on the day of birth. This observation suggests that this complex matures earlier than surrounding regions of the bulb. The presence of distinct activity in the MGC does not rule out the participation of the main or accessory olfactory bulb in transmitting some components of the information about odor suckling cues.

The 2DG data support the postulate that the MGC plays a crucial role in mediating information about the odor cue involved in suckling behavior. The specialization of a glomerulus within the mammalian olfactory pathway for pheromonal information has an interesting parallel in the insect, where a macroglomerulus, present only in males, is innervated by the dendrites of cells which respond to the female sex attractant bombykol (Matsumoto and Hildebrand, 1981; Tolbert and Hildebrand, 1981). Since the stimulus conditions prevalent during suckling behavior, including room air, maternal odors, etc., are very complex, the specific odor that elicits $2 \mathrm{DG}$ uptake in the MGC is not presently known.

The present results thus identify the MGC as a distinct, histologically identifiable part of the olfactory pathway and provide evidence for its early functional maturation in the processing of odors that are of significance to the neonatal rat. From a comparative point of view, it would be of interest to know whether the olfactory system is unique in this respect or whether other sensory systems also exhibit specialized regions of early functional maturation associated with developmentally significant behaviors (Jacobson, 1978).

\section{References}

Alberts, J. R., and B. May (1980a) Development of nasal respiration and sniffing in the rat. Physiol. Behav. 24: 957963.

Alberts, J. R., and B. May (1980b) Ontogeny of olfaction: Development of the rat's sensitivity to urine and amyl acetate. Physiol. Behav. 24: 965-970.
Altman, J. (1966) Autoradiographic and histological studies of postnatal neurogenesis. II. A longitudinal investigation of the kinetics, migration and transformation of cells incorporating tritiated thymidine in infant rats, with special reference to postnatal neurogenesis in some brain regions. J. Comp. Neurol. 128: 431-474.

Astic, L., and D. Saucier (1982) Ontogenesis of the functional activity of rat olfactory bulb: Autoradiographic study with the 2-deoxyglucose method. Dev. Brain Res. 2: 243-256.

Blass, E. M., and M. H. Teicher (1980) Suckling. Science 210: 15-22.

Bojsen-Moller, F., and J. Fahrenkrug, (1971) Nasal swell bodies and cyclic changes in the air passage of rat and rabbit nose. J. Anat. 101: 25-37.

Goochee, C., W. Rasband, and L. Sokoloff (1980) Computerized densitometry of $\left({ }^{14} \mathrm{C}\right)$ deoxyglucose autoradiographs. Ann. Neurol. 7: 359-370.

Grafe, M. R., and C. M. Leonard (1980) Developmental changes in the topographical distribution of cells contributing to the lateral olfactory tract. Soc. Neurosci. Abstr. 6: 637.

Greer, C. A., W. B. Stewart, M. H. Teicher, J. S. Kauer, and G. M. Shepherd (1980) Correlation of histology and 2-deoxyglucose uptake in the developing rat olfactory bulb. Soc. Neurosci. Abstr. 6: 306 .

Greer, C. A., K. Mori, and G. M. Shepherd (1981a) Localization of synaptic responses in the in vitro turtle olfactory bulb using the ${ }^{14} \mathrm{C}$-2-deoxyglucose method. Brain Res. 217: 295 303.

Greer, C. A., W. B. Stewart, J. S. Kauer, and G. M. Shepherd (1981b) Topographical and laminar localization of 2-deoxyglucose uptake in rat olfactory bulb induced by electrical stimulation of olfactory nerves. Brain Res. 217: 279-293.

Hinds, J. W. (1968a) Autoradiographic study of histogenesis in the mouse olfactory bulb. I. Time of origin of neurons and neuroglia. J. Comp. Neurol. 134: 287-304.

Hinds, J. W. (1968b) Autoradiographic study of histogenesis in the mouse olfactory bulb. II. Cell proliferation and migration. J. Comp. Neurol. 134: 305-322.

Hinds, J. W., and P. L. Hinds (1976a) Synapse formation in the Inouse olfactory bulb. I. Quantitative studies. J. Comp. Neurol. 169: $15-40$.

Hinds, J. W., and P. L. Hinds (1976b) Synapse formation in the mouse olfactory bulb. II. Morphogenesis. J. Comp. Neurol. 169: 41-62.

Jacobson, M. (1978) Developmental Neurobiology, Plenum Press, New York.

Jourdan, F., A. Duveau, L. Astic, and A. Holley (1980) Spatial distribution of ${ }^{14} \mathrm{C}$-2-deoxyglucose uptake in the olfactory bulbs of rats stimulated with two different odours. Brain Res. 188: 139-154.

Kennedy, C., M. H. Des Rosiers, J. W. Jehle, M. Reivich, F. R. Sharp, and L. Sokoloff (1975) Mapping of functional neural pathways by autoradiographic survey of local metabolic rate with ${ }^{14} \mathrm{C}$-2-deoxyglucose. Science 187: 850-853.

Lancet, D., C. A. Greer, J. S. Kauer, and G. M. Shepherd (1982) Mapping of odor related neuronal activity in the olfactory bulb by high-resolution 2-deoxyglucose autoradiography. Proc. Natl. Acad. Sci. U. S. A. 79: 670-674.

Leon, M. (1974) Maternal pheromone. Physiol. Behav. 13: 441443.

Leon, M., B. G. Galef, and J. H. Behse (1972) Establishment of pheromonal bonds and diet choice in young rats by odor preexposure. Physiol. Behav. 18: 387-391.

Mata, M., D. Fink, H. Gainer, C. Smith, L. Davidsen, H. Savaki, W. Schwartz, and L. Sokoloff (1980) Activity-dependent energy metabolism in rat posterior pituitary primarily reflects sodium pump activity. J. Neurochem. 34: 213-215.

Math, F., and J. L. Davrainville (1980a) Electrophysiological study on the postnatal development of mitral cell activity in 
the rat olfactory bulb. Brain Res. 190: 243-247.

Math, F., and J. L. Davrainville (1980b) Electrophysiological study on the postnatal development of mitral cell activity in the rat olfactory bulb. Influence of undernutrition. Brain Res. 194: 223-227.

Matsumoto, S. G., and J. G. Hildebrand (1981) Olfactory mechanisms in the moth Manducca sexta: Response characteristics and morphology of central neurons in the antennal lobes. Proc. R. Soc. Lond. (Biol.) 213: 249-277.

Monti-Graziadei, G. A., R. S. Stanley, and P. P. C. Graziadei (1980) The olfactory marker protein in the olfactory system of the mouse during development. Neuroscience 5: 1239 1252.

Proshansky, E., J. S. Kauer, W. B. Stewart, and M. D. Egger (1980) 2-Deoxyglucose uptake in cat spinal cord during sustained and habituated activity in the plantar cushion reflex pathway. J. Comp. Neurol. 194: 505-517.

Rosselli-Austin, L., and J. Altman (1979) The postnatal development of the main olfactory bulb of the rat. J. Dev. Physiol. 1: 295-313.

Rudy, J. W., and M. D. Cheatle (1977) Odor aversion learning in neonatal rats. Science 198: 845-846.

Salas, M., C. Guzman-Flores, and S. Schapiro (1969) An ontogenetic study of olfactory bulb electrical activity in the rat. Physiol. Behav. 4: 699-703.

Schwartz, W., C. Smith, L. Davidsen, H. Savaki, L. Sokoloff, M. Mata, D. Fink, and H. Gainer (1979) Metabolic mapping of functional activity in the hypothalamo-neurohypophysial system of the rat. Science 205: 723-725.

Sharp, F. R. (1976) Relative cerebral metabolic rates of neu- ronal perikarya and neuropil determined with 2-deoxyglucose in resting and swimming rat. Brain Res. 110: 127-140.

Sharp, F., J. Kauer, and G. M. Shepherd (1975) Local sites of activity related glucose metabolism in the rat olfactory bulb during olfactory stimulation. Brain Res. 98: 596-600.

Sharp, F., J. Kauer, and G. M. Shepherd (1977) Laminar analysis of 2-deoxyglucose uptake in olfactory bulb and olfactory cortex of rabbit and rat. J. Neurophysiol. 40: 800-813.

Singh, D. N. P., and E. J. H. Nathaniel (1978) Postnatal development of mitral cell perikaryon in the olfactory bulb of the rat. A light and ultrastructural study. Anat. Rec. 189: $413-432$.

Stewart, W. B., J. S. Kauer, and G. M. Shepherd (1979) Functional organization of the rat olfactory bulb analyzed by the 2-deoxyglucose method. J. Comp. Neurol. 185: 715-734.

Teicher, M. H., and E. M. Blass (1976) Suckling in newborn rats: Eliminated by nipple lavage, reinstated by pup saliva. Science 193: 422-425.

Teicher, M. H., and E. M. Blass (1978) The role of olfaction and amniotic fluid in the first suckling response of newborn albino rats. Science 198: 635-636.

Teicher, M. H., W. B. Stewart, J. S. Kauer, and G. M. Shepherd (1980) Suckling pheromone stimulation of a modified glomerular region in the developing rat olfactory bulb revealed by the 2-deoxyglucose method. Brain Res. 194: 530-535.

Tolbert, L. P., and J. G. Hildebrand (1981) Organization and synaptic ultrastructure of glomeruli in the antennal lobes of the moth Manducca sexta: A study using thin sections and freeze fracture. Proc. R. Soc. Lond. (Biol.) 213: 279-301. 